www.jmscr.igmpublication.org

Impact Factor 5.84

Index Copernicus Value: 71.58

ISSN (e)-2347-176x ISSN (p) 2455-0450

crossref DOI: _https://dx.doi.org/10.18535/jmscr/v5i12.33

Journal Of Medical Science And Clinical Research

\title{
Feasibility of Calot's Triangle Dissection Outcome as Easy versus Difficult Laparoscopic Cholecystectomy Based on Clinico radiological Assessment
}

\author{
Authors \\ Prof. Dr Braja Mohan Mishra ${ }^{1}$, Dr Fakira Mohan Sahu ${ }^{2}$ \\ ${ }^{1}$ HOD \& Professor, Department Of General Surgery, VIMSAR, Burla, Odisha, India \\ ${ }^{2}$ Post Graduate Student, Department Of General Surgery, VIMSAR, Burla, Odisha, India
}

\begin{abstract}
Laparoscopic cholecystectomy $(L C)$ is the gold standard treatment for symptomatic cholelithiasis. However conversion is inevitable in difficult cases among all laparoscopic cholecystectomies $1-13 \%$ requires conversion to open conversion. Several factors have been implicated with a difficult case, but no reliable criteria are available yet to identify patients preoperatively with a difficult Laparoscopic cholecystectomy in feasibility of Calot'striangle dissection.

Aim: To predict the feasibility of Calot's triangle dissection outcome by clinico-radiological assessment in easy verses difficult laparoscopic cholecystectomy.

Material and Methods: This was a prospective study conducted from November 2015 to October 2017. Total of 63 patients meeting the inclusion criteria undergone laparoscopic cholecystectomy were included in the study. Following parameters were assessed preoperatively such as BMI, number of attacks of cholecystitis, previous abdominal surgery, total leucocyte count and compare with intraoperative findings as "easy laparoscopic cholecystectomy" and "difficult laparoscopic cholecystectomy". The statistical analysis was done using Chi- squretest.

Results: Out of 63 patients difficult laparoscopic cholecystectomy was seen in 25 (39.7\%) patients and 7 (11.1\%) patients required conversion to open cholecystectomy. Significant predictors of difficult and conversion were BMI, TLC, ultrasonographic findings of presence of pericholecystic fluid collection, multiple stone or stones $\geq 20 \mathrm{~mm}$ impacted in Hartmann's pouch, adhesion in Calot's triangle and gallbladder perforation.

Conclusion: with preoperative clinical and ultrasonographic parameters, proper patients selection can be made to help predict difficult laparoscopic cholecystectomy and a likelihood of conversion to open cholecystectomy. Patients and relatives can be counseled preoperatively for the possibility of difficult operation, prolonged hospital stay and increased cost in predicted difficult case.

Keywords: Calot's Triangle, Cholesystectomy, Laparoscopy, Easy, Difficult, Open Conversion, Ultrasonographic Parameters.
\end{abstract}

\section{Introduction}

Gall stone disease is one of the most common problems affecting the digestive tract.The National Institute of Health (NIH) consensus development conference in the year 1992 concluded that laparoscopic cholecystectomy provides a safe and effective treatment for most patients with symptomatic gallstones ${ }^{1}$.At present 
Laparoscopic cholecystectomy (LC) is the gold standard treatment for symptomatic cholelithiasis. It has many advantages over open cholecystectomy in terms of minimal postoperative pain, shorter hospital stay, better cosmetics and early recovery. As the experience with LC is increasing throughout the world, selection criteria have become more liberal.Attempts can be made in all cases of gall stone diseases with laparoscopic procedure except for patients with bleeding diathesis, carcinoma gallbladder and patients not fit for general anaesthesia.

However, of all Laparoscopic cholecystectomies, $1-13 \%$ requires conversion to an open for various reasons $^{2}$. Thus, for surgeons it would be helpful to establish criteria that would predict difficult laparoscopic cholecystectomy on the basis of feasible dissection of Calot's triangle and conversion preoperatively.But there is no clear consensus among the laparoscopic surgeons regarding the parameters predicting the difficult dissection and conversion to open cholecystectomy. Laparoscopic cholecystectomy (LC) may be rendered 'Difficult' by various problems encountered during surgery, such as difficulties in accessing the peritoneal cavity, creating a pneumoperitoneum, dissecting the gallbladder (GB), or extracting the excised GB. On the basis of clinico-radiological findings, surgeons can select the cases appropriate for their skills aiming at reducing operative complications and minimizing the waste of operating time available. Patients with long-standing disease and previous bouts of cholecystitis or pancreatitis are at higher risk of experiencing a difficult procedure or conversion and may be at increased risk of bile duct injury or injury to the adjoining viscera. Preoperative information of possible intraoperative complications such as uncontrollable bleeding or unclear anatomy, conversion to open surgery will give extra benefits. It can be helpful to raise level of cautiousness and establish a criterion that could assess the risk for conversion preoperatively. It would be helpful to accurately identify an individual patient's risk for conversion based on preoperative information can result in more meaningful and accurate preoperative counseling, improved operating room scheduling and efficiency.This may improve patient safety by minimizing time to conversion, and better mental preparation of surgeons and patients also.

Efficiency and safety of LC depends on the experience and expertise of the surgeon and on the underlying pathology. Preoperative knowledge of risk factors that indicate the occurrence of difficulties in dissection of Calot's triangle is of great importance for the safety of patients.

The present study is an attempt to predict the feasibility of Calot's triangle dissection outcome by clinico-radiological assessment in easy verses difficult laparoscopic cholecystectomy.

\section{Material and Methods}

The present prospective study regarding "Feasibility Of Calot's Triangle Dissection Outcome As Easy Versus Difficult Laparoscopic Cholecystectomy Based On Clinicoradiological Assessment" was undertaken in63 patients with acute calculous cholecystitis and chronic calculous cholecystitisin the Department of Surgery, VSS Institute of Medical Sciences and Research, Burla, Odisha over a period of two years from November 2015 to October 2017.patients with the following criteria were excluded from this study: (i)Acalculous Cholecystitis; (ii) Cholangitis; (iii) Common Bile Duct Stone; (iv) Diabetes Mellitus; (v) Ischemic Heart Disease; (vi) Congestive Cardiac Failure ;(vii) Chronic Renal Diseases.

The study was approved by the institutional review board.A detailed history was taken and thorough clinical examinations of all the patients were performed. Information about age, sex and body mass index (BMI) of the patients; previous abdominal surgery; past history of acute attack of cholecystitis and total leucocyte count; ultrasonographic findings was noted. Preoperative ultrasonography was performed on the morning of the surgery. Four ultrasonographic parameters were studied, namely GB wall thickness (more 


\section{JMSCR Vol||05||Issue||12||Page 31413-31425||December}

than $3 \mathrm{~mm}$ thick GB wall thickness was predicted to be a difficult laparoscopic cholecystectomy); number of stones $\geq 2$ and stone impacted in Hartmann's pouch; pericholecystic fluid collection and intra-operative causes for the conversion of LC to OC namely: Adhesions in Calot's triangle and gall bladder perforation with bile leak were evaluated. All routine investigations including liver function test and coagulation profile were done. The selected patients were then told about the procedure and written informed consent was taken. Patients were also informed about the conversion to OC.

\section{Operative Procedure}

Patients underwent LC by the same surgical team that was blinded to the results of the pre-operative ultrasonography. LC was performed by trained general surgeons under supervision. Easy and difficulties were assessed in terms of age, sex, BMI, number of attacks of acute cholecystitis, previous abdominal surgery, total leucocyte count, GB wall thickness, number of GB stones, biliary anatomy, pericholecystic fluid collection, adhesions, unclear Calot's anatomy and bleeding or perforation during peeling off GB from the bed. Time was not considered as a factor to define difficult surgery.

\section{Statistical Analysis}

Data analysis was performed using the Statistical Package for the Social Sciences (SPSS version 19). A value of $\mathrm{p}<0.05$ was considered statistically significant derived by Chi-square test.

\section{Results}

This prospective study of laparoscopic cholecystectomy in acute calculous cholecystitis and chronic calculous cholecystitis was done in a period of two years from NOVEMBER, 2015 to OCTOBER, 2017 in the Department of General Surgery, VIMSAR, Burla. A total of 63 cases of cholecystitis, with proved gall stones by ultrasound, admitted to the Surgery indoor were studied.
Table-1(a) Age and sex distribution

\begin{tabular}{|l|c|c|c|}
\hline Age group in year & Male & Female & Total \\
\hline $20-29$ & 3 & 18 & $21(33.3 \%)$ \\
\hline $30-39$ & 2 & 13 & $15(23.8 \%)$ \\
\hline $40-49$ & 2 & 13 & $15(23.8 \%)$ \\
\hline $50-59$ & 2 & 5 & $7(11.1 \%)$ \\
\hline $60-69$ & 1 & 4 & $5(8.0 \%)$ \\
\hline Total $(\%)$ & $10(15.9)$ & $53(84.1)$ & $63(100 \%)$ \\
\hline
\end{tabular}

Age of patient ranged from 20 to 69 years with mean age of 38.35 years. The youngest female was 23 years old \& youngest male was 22 years old. The oldest female was 68 years \& oldest male was 67 years old.

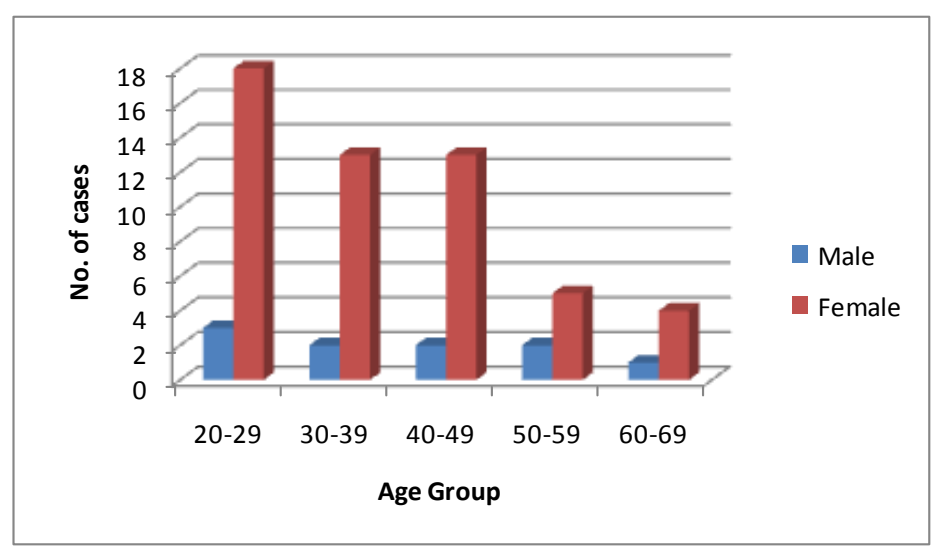

Table 1(b) Age wise distribution of cholecystectomy

\begin{tabular}{|c|c|c|c|c|}
\hline $\begin{array}{c}\text { Age in } \\
\text { years }\end{array}$ & $\begin{array}{c}\text { Easy LC } \\
(\text { ELC) }\end{array}$ & $\begin{array}{c}\text { Difficult LC } \\
(\text { DLC })\end{array}$ & $\begin{array}{c}\text { Open } \\
\text { Conversion } \\
(\text { OC) }\end{array}$ & Total \\
\hline$<50$ yrs. & $25(49 \%)$ & $21(41.2 \%)$ & $5(9.8 \%)$ & $51(81 \%)$ \\
\hline$>50$ yrs. & $6(50 \%)$ & $4(33.3 \%)$ & $2(16.7 \%)$ & $12(19 \%)$ \\
\hline Total & $\begin{array}{c}31 \\
(49.2 \%)\end{array}$ & $25(39.7 \%)$ & $7(11.1 \%)$ & $63(100 \%)$ \\
\hline
\end{tabular}

Fifty one $(81 \%)$ patients were $<50$ years of age out of which $21(41.2 \%)$ patients had difficult LC(DLC) and 5 (9.8\%) patients required conversion. Twelve (19\%) patients were >50 years of age and difficult LC was seen in 4 (33.3\%) patients with $2(16.7 \%)$ patients requiring conversion. This was statistically insignificant $(\mathrm{p}=0.864)$ (Fig. 1a and 1b). 


\section{JMSCR Vol||05||Issue||12||Page 31413-31425||December}
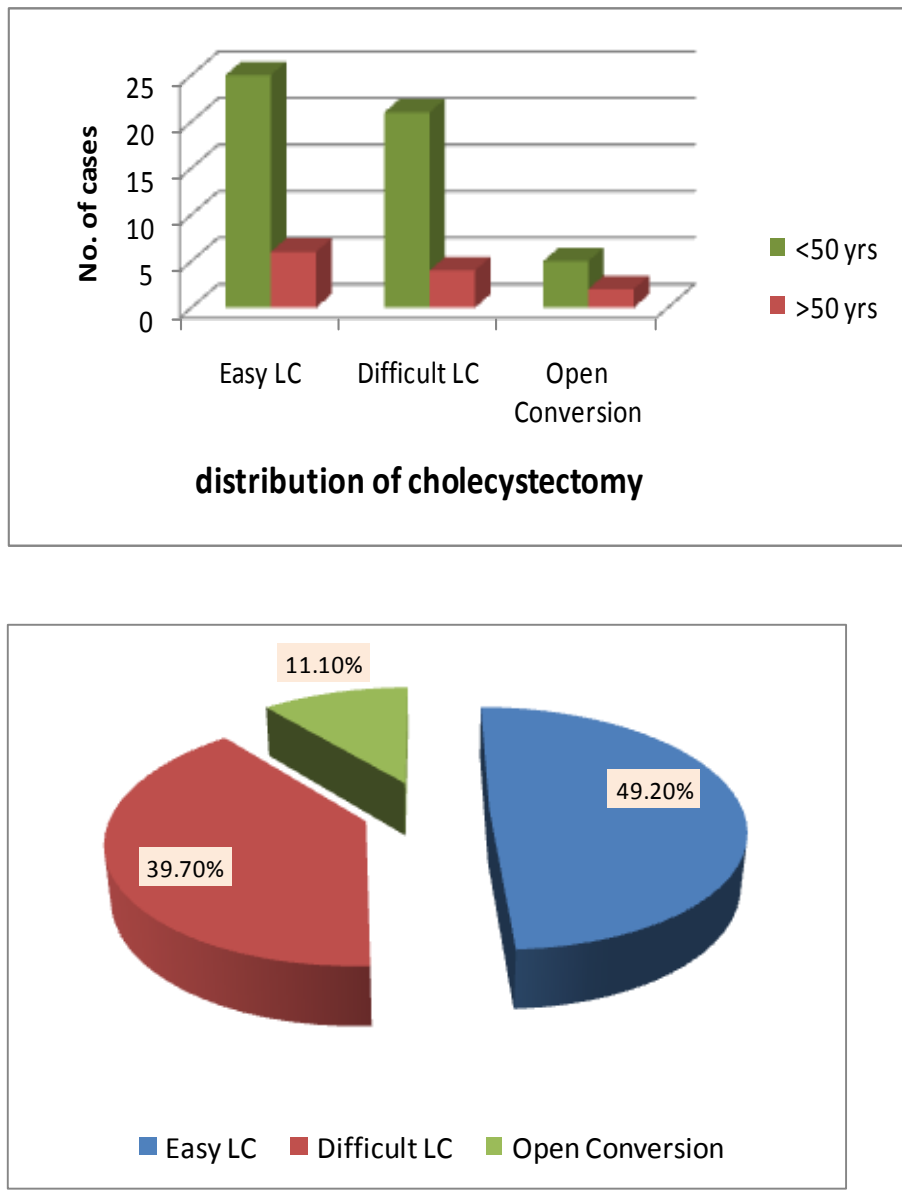

Table 2 Gender Distribution and Relationship with Easy LC, Difficult LC and open conversion

\begin{tabular}{|l|c|c|c|}
\hline Gender & Difficulty LC & Easy LC & Open Conversion \\
\hline Male (n=10) & $3(30 \%)$ & $7(70 \%)$ & $0(0 \%)$ \\
\hline Female (n=53) & $22(41.5 \%)$ & $34(45.3 \%)$ & $7(13.2 \%)$ \\
\hline
\end{tabular}

There were $53(84.1 \%)$ female and $10(15.9 \%)$ male patients, with female: male ratio 5.3:1. Out of 53 female, difficult LC was encountered in 22 patients $(41.5 \%)$ and only $7(13.2 \%)$, required conversion. Out of 10 male patients, difficulty was seen in patients $3(30 \%)$, however no patients required conversion. Thus the incidence of difficult cholecystectomy was more in females as compared to males, being $41.5 \%$ and $30 \%$ respectively. It was not statistically significant (Table 2).

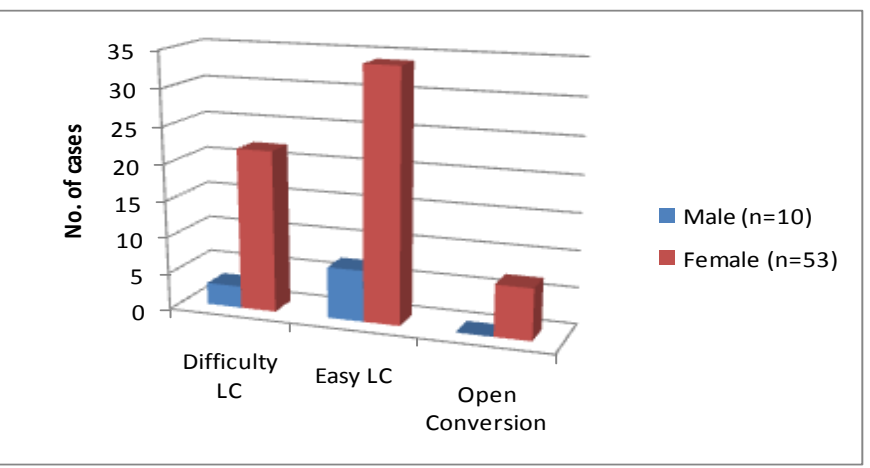

Table - 3 Relationship between BMI, Easy LC, Difficult LC and Conversion to OC

\begin{tabular}{|c|c|c|c|c|c|c|c|c|}
\hline $\begin{array}{l}\text { BMI } \\
(\mathrm{kg} / \mathrm{m} 2)\end{array}$ & $\begin{array}{c}\text { Difficu } \\
\text { lt LC } \\
(\%)\end{array}$ & $\begin{array}{c}\text { Easy } \\
\text { LC }(\%)\end{array}$ & $\begin{array}{c}\text { Total } \\
(\%)\end{array}$ & $\begin{array}{c}\mathrm{p} \\
\text { value }\end{array}$ & $\begin{array}{c}\text { Open } \\
\text { Conve } \\
\text { rsion } \\
(\%) \\
\end{array}$ & $\begin{array}{l}\mathrm{LC} \\
(\%)\end{array}$ & $\begin{array}{l}\text { Total } \\
(\%)\end{array}$ & $\begin{array}{l}\mathrm{P} \\
\text { Valu } \\
\mathrm{e}\end{array}$ \\
\hline $\begin{array}{l}\text { Normal } \\
\text { weight } \\
(18.1-25)\end{array}$ & $\begin{array}{c}18 \\
(34)\end{array}$ & $35(66)$ & $\begin{array}{c}53 \\
(84)\end{array}$ & \multirow{4}{*}{0.033} & $\begin{array}{c}4 \\
(7.6)\end{array}$ & $\begin{array}{c}49 \\
(92.4)\end{array}$ & $\begin{array}{l}53 \\
(100)\end{array}$ & \multirow{4}{*}{0.038} \\
\hline $\begin{array}{l}\text { Over } \\
\text { weight } \\
(25.1-30)\end{array}$ & $\begin{array}{c}7 \\
(70)\end{array}$ & $3(30)$ & $\begin{array}{c}10 \\
(16)\end{array}$ & & $\begin{array}{c}3 \\
(30)\end{array}$ & $\begin{array}{c}7 \\
(70)\end{array}$ & $\begin{array}{l}10 \\
(100)\end{array}$ & \\
\hline $\begin{array}{l}\text { Obese } \\
(\geq 30.1)\end{array}$ & $\begin{array}{c}0 \\
(0)\end{array}$ & $\begin{array}{c}0 \\
(0)\end{array}$ & $\begin{array}{c}0 \\
(0)\end{array}$ & & $\begin{array}{c}0 \\
(0)\end{array}$ & $\begin{array}{c}0 \\
(0)\end{array}$ & $\begin{array}{l}0 \\
(0)\end{array}$ & \\
\hline Total & $\begin{array}{c}25 \\
(39.70)\end{array}$ & $\begin{array}{c}38 \\
60.30)\end{array}$ & $\begin{array}{c}63 \\
(100)\end{array}$ & & $\begin{array}{c}7 \\
(11.2)\end{array}$ & $\begin{array}{c}56 \\
(88.8)\end{array}$ & $\begin{array}{l}63 \\
(100)\end{array}$ & \\
\hline
\end{tabular}

BMI of patients were assessed as shown in Table 3. BMI in this study group ranged from 15.60 to $28 \mathrm{~kg} / \mathrm{m}^{2}$ with mean of $22.07 \pm 2.87$. Out of 63 patients, 53 (84\%) had normal BMI of 25 $\mathrm{kg} / \mathrm{m}^{2}$.In this group there were $18(34 \%)$ patients with difficult LC, out of which only $4(7.6 \%)$ patients required conversion. BMI of 25.1 to 30 $\mathrm{kg} / \mathrm{m}^{2}$ was seen in $10(16 \%)$ patients where 7 $(70 \%)$ patients had difficulty LC and $3(30 \%)$ patients required conversion. There was no case with BMI $\geq 30.1 \mathrm{~kg} / \mathrm{m}^{2}$ in this study. These findings were statistically significant ( $\mathrm{p}$ value $=0.033$ and 0.038 respectively) (Table 3 ).

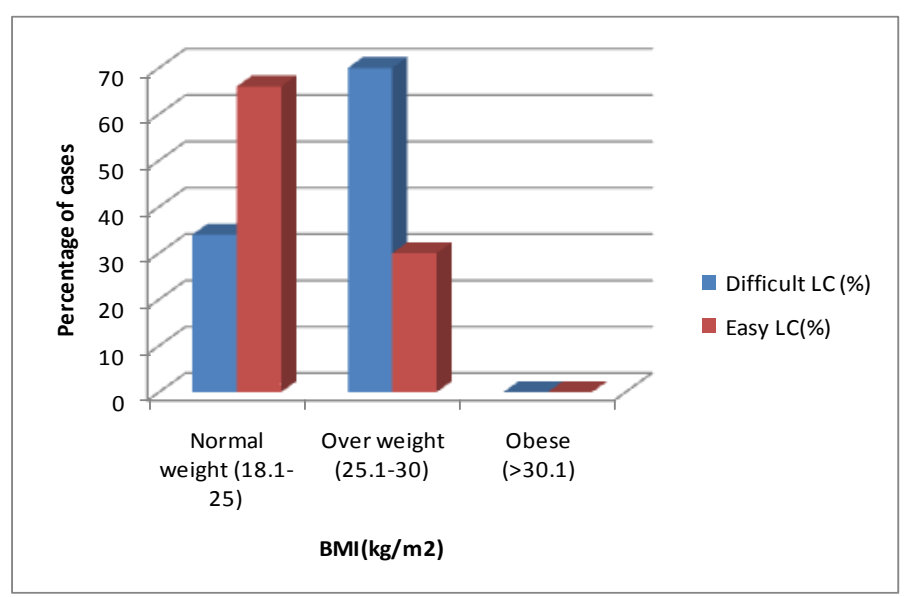




\section{JMSCR Vol||05||Issue||12||Page 31413-31425||December}

Table 4 Relationship between Previous abdominal surgery (PAS), Easy LC, Difficult LC and Conversion to OC

\begin{tabular}{|c|c|c|c|c|c|c|c|c|}
\hline $\begin{array}{l}\text { Previous } \\
\text { abdominal } \\
\text { surgery }\end{array}$ & $\begin{array}{c}\text { DLC } \\
(\%)\end{array}$ & $\begin{array}{c}\text { E.LC } \\
(\%)\end{array}$ & Total & $\begin{array}{c}\mathrm{p} \\
\text { value }\end{array}$ & $\begin{array}{l}\mathrm{OC} \\
(\%)\end{array}$ & $\begin{array}{l}\mathrm{LC} \\
(\%)\end{array}$ & Total & $\begin{array}{c}\mathrm{P} \\
\text { Value }\end{array}$ \\
\hline NO & $\begin{array}{c}23 \\
(39.7) \\
\end{array}$ & $\begin{array}{c}35 \\
(60.3) \\
\end{array}$ & 58 & \multirow{3}{*}{1} & $\begin{array}{c}7 \\
(12) \\
\end{array}$ & $\begin{array}{c}51 \\
(88) \\
\end{array}$ & 58 & \multirow{3}{*}{0.409} \\
\hline Yes & $\begin{array}{c}2 \\
(40) \\
\end{array}$ & $\begin{array}{c}3 \\
(60) \\
\end{array}$ & 5 & & $\begin{array}{c}0 \\
(0)\end{array}$ & $\begin{array}{c}5 \\
(100) \\
\end{array}$ & 5 & \\
\hline TOTAL & 25 & 38 & 63 & & 7 & 56 & 63 & \\
\hline
\end{tabular}

There were $5(8 \%)$ patients with previous history of different abdominal surgery. Among them 2 (40\%)patients had difficulty during the procedure, however no patients required conversion to OC. Rest of the 58 (92\%) patients had without PAS, out of which $23(39.7 \%)$ patients had difficult LC and $7(12 \%)$ patients required conversion to OC. These findings were statistically insignificant ( $\mathrm{p}$ value $=1$ and 0.409 respectively)(Table 4).

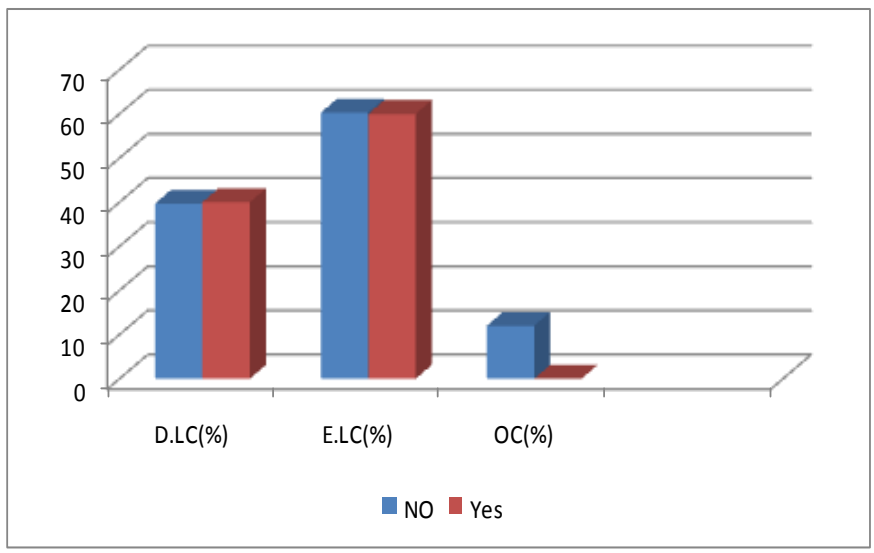

Table 5 Relationship between Number of attacks of acute cholecystitis Easy LC, Difficult LC and Conversion to OC

\begin{tabular}{|l|l|l|l|l|l|l|}
\hline $\begin{array}{l}\text { No. of } \\
\text { attack }\end{array}$ & $\begin{array}{l}\text { DLC } \\
(\%)\end{array}$ & $\begin{array}{l}\text { ELC } \\
(\%)\end{array}$ & $\begin{array}{l}\text { Total } \\
(\%)\end{array}$ & $\begin{array}{l}\text { OC } \\
(\%)\end{array}$ & $\begin{array}{l}\text { LC } \\
(\%)\end{array}$ & $\begin{array}{l}\text { Total } \\
(\%)\end{array}$ \\
\hline No attack & $\begin{array}{l}11 \\
(33.3)\end{array}$ & $\begin{array}{l}22 \\
(66.3)\end{array}$ & $\begin{array}{l}33 \\
(52.4)\end{array}$ & $\begin{array}{l}3 \\
(9.1)\end{array}$ & $\begin{array}{l}30 \\
(90.9)\end{array}$ & $\begin{array}{l}33 \\
(52.4)\end{array}$ \\
\hline 1 attack & $\begin{array}{l}10 \\
(43.5)\end{array}$ & $\begin{array}{l}13 \\
(56.5)\end{array}$ & $\begin{array}{l}23 \\
(36.5)\end{array}$ & $\begin{array}{l}2 \\
(8.7)\end{array}$ & $\begin{array}{l}21 \\
(91.3)\end{array}$ & $\begin{array}{l}23 \\
(36.5)\end{array}$ \\
\hline$\geq 2$ attack & $\begin{array}{l}4 \\
(57.1)\end{array}$ & $\begin{array}{l}3 \\
(42.9)\end{array}$ & $\begin{array}{l}7 \\
(11.1)\end{array}$ & $\begin{array}{l}2 \\
(28.6)\end{array}$ & $\begin{array}{l}5 \\
(71.4)\end{array}$ & $\begin{array}{l}7 \\
(11.1)\end{array}$ \\
\hline Total & $\begin{array}{l}25 \\
(39.70)\end{array}$ & $\begin{array}{l}38 \\
(60.30)\end{array}$ & $\begin{array}{l}63 \\
(100)\end{array}$ & $\begin{array}{l}7 \\
(11.2)\end{array}$ & $\begin{array}{l}56 \\
(88.8)\end{array}$ & $\begin{array}{l}63 \\
(100)\end{array}$ \\
\hline
\end{tabular}

Out of 63 patients, there was no history of acute cholecystitis in $33(52.4 \%)$ patients. In this group difficult LC were encountered in $11(33.3 \%)$ patients and $3(9.1 \%)$ patients required the conversion. Single attack of acute cholecystitis was seen in $23(36.5 \%)$ patients and out of which $10(43.5 \%)$ patients had difficult LC and $2(8.7 \%)$ patients required conversion. Two or more attacks of acute cholecystitis were seen in $7(11.1 \%)$ patients with $4(57.1 \%)$ patients having difficulty LC and in $2(28.6 \%)$ patients, conversion was done. These findings were statistically significant (p-value<0.05) (Table 5).

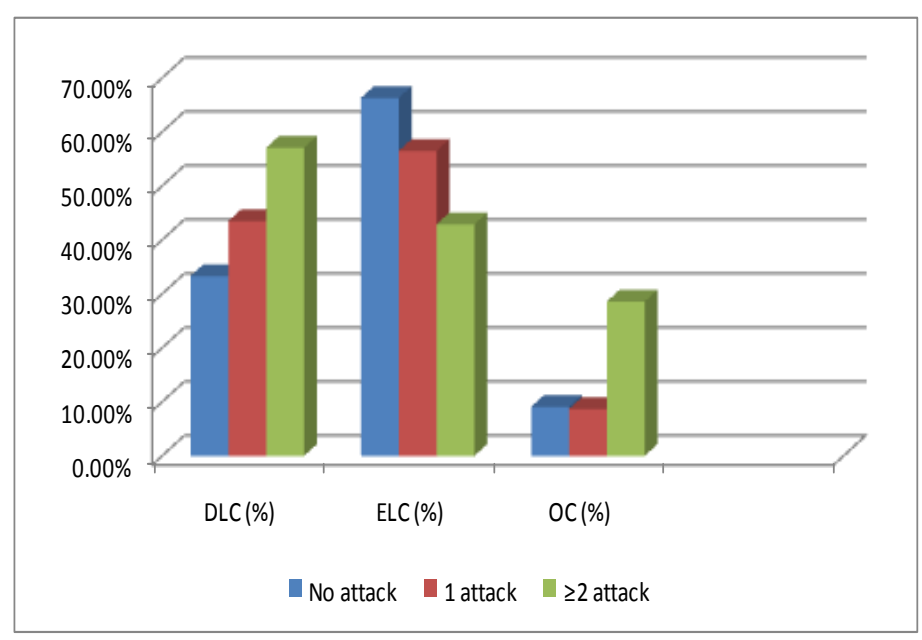

Table 6 Relationship between TLC, Easy LC,

Difficult LC and Conversion to OC

\begin{tabular}{|c|c|c|c|c|c|c|c|c|}
\hline $\begin{array}{l}\text { Total } \\
\text { Leuckocy } \\
\text { te Count }\end{array}$ & $\begin{array}{l}\text { DLC } \\
(\%)\end{array}$ & ELC & $\begin{array}{l}\text { Total } \\
(\%)\end{array}$ & $\begin{array}{l}\mathrm{p} \\
\text { value }\end{array}$ & $\begin{array}{l}\mathrm{OC} \\
(\%)\end{array}$ & $\begin{array}{l}\mathrm{LC} \\
(\%)\end{array}$ & $\begin{array}{l}\text { Total } \\
(\%)\end{array}$ & $\begin{array}{l}\mathrm{P} \\
\text { Valu } \\
\mathrm{e} \\
\end{array}$ \\
\hline $\begin{array}{l}<11,000 / \\
\mathrm{mm}^{3}\end{array}$ & $\begin{array}{l}15 \\
(30)\end{array}$ & $\begin{array}{l}35 \\
(70)\end{array}$ & $\begin{array}{l}50 \\
(79.4)\end{array}$ & \multirow{3}{*}{0.002} & $\begin{array}{l}3 \\
(6)\end{array}$ & $\begin{array}{l}47 \\
(94)\end{array}$ & $\begin{array}{l}50 \\
(79.4)\end{array}$ & \multirow{3}{*}{$\begin{array}{l}0.01 \\
1\end{array}$} \\
\hline $\begin{array}{l}\geq 11,000 / \\
\mathrm{mm}^{3}\end{array}$ & $\begin{array}{l}10 \\
(76.9)\end{array}$ & $\begin{array}{l}3 \\
(23.1)\end{array}$ & $\begin{array}{l}13 \\
(20.6)\end{array}$ & & $\begin{array}{l}4 \\
(30.7)\end{array}$ & $\begin{array}{l}9 \\
(69.3)\end{array}$ & $\begin{array}{l}13 \\
(20.6)\end{array}$ & \\
\hline TOTAL & 25 & 38 & 63 & & 7 & 56 & 63 & \\
\hline
\end{tabular}

TLC of patient was assessed as shown in Table6. TLC in this study group ranged from $7940 / \mathrm{mm}^{3}$ to $12900 / \mathrm{mm} 3$ with the mean of $10200 / \mathrm{mm}^{3}$. Out of 63 patients, $50(79.4 \%)$ had normal TLC of $<11000 / \mathrm{mm}^{3}$. In this group there were $15(30 \%)$ patients with difficult LC, out of which only 3 $(6 \%)$ patients required conversions. TLC of $\geq 11000 / \mathrm{mm}^{3}$ was seen in $13(20.6 \%)$ patients where $10(76.9 \%)$ patients had difficulty LC and 4 (30.7\%) patients required conversion. These findings were statistically significant (pvalue $=0.002$ and 0.011 respectively) $($ Table 6). 


\section{JMSCR Vol||05||Issue||12||Page 31413-31425||December}

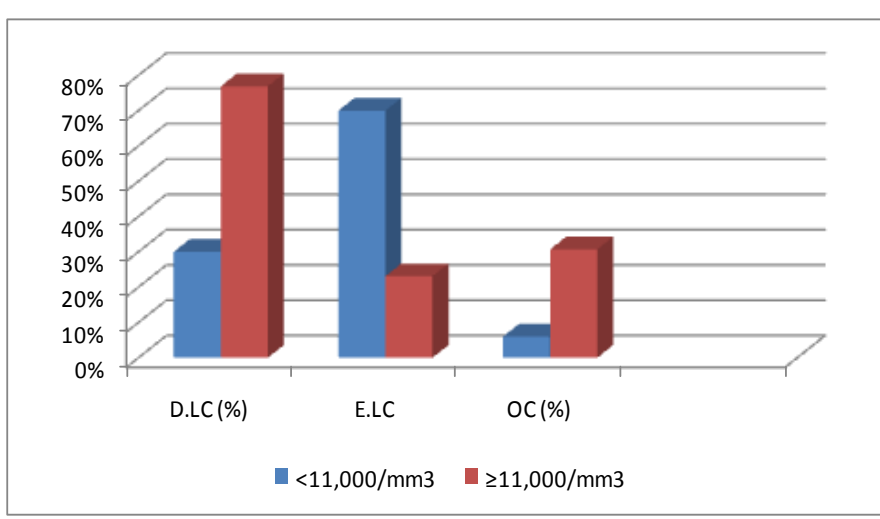

Table 7 Relationship between Pericholecystic fluid collections, Easy LC, Difficult LC and Conversion to $\mathrm{OC}$

\begin{tabular}{|c|c|c|c|c|c|c|c|c|}
\hline $\begin{array}{l}\text { Pericholecystic } \\
\text { fluid collection }\end{array}$ & DLC & ELC & Total & $\begin{array}{l}P \\
\text { value }\end{array}$ & $\mathrm{OC}$ & LC & Total & $\begin{array}{l}\text { P } \\
\text { Value }\end{array}$ \\
\hline $\mathrm{NO}(\mathrm{n}=51)$ & 14 & 37 & 51 & \multirow{3}{*}{0.0001} & 2 & 49 & 51 & \multirow{3}{*}{0.0001} \\
\hline Yes $(n=12)$ & 11 & 1 & 12 & & 5 & 7 & 12 & \\
\hline TOTAL & 25 & 38 & 63 & & 7 & 56 & 63 & \\
\hline
\end{tabular}

There were 12 (19\%) patients with pericholecystic fluid collection in ultrasounogrphy among them $11(91.7 \%)$ patients had difficulty during the procedure and $5(41.7 \%)$ patients required conversion to OC. Rest of the 51 (80.9\%) patients had without pericholecystic fluid collection, out of which 14 (27.4\%) patients had difficult LC and 2 (4\%) patients required conversion to OC. These findings were statistically significant (pvalue $=0.0001$ and 0.0001 respectively) (Table 7).

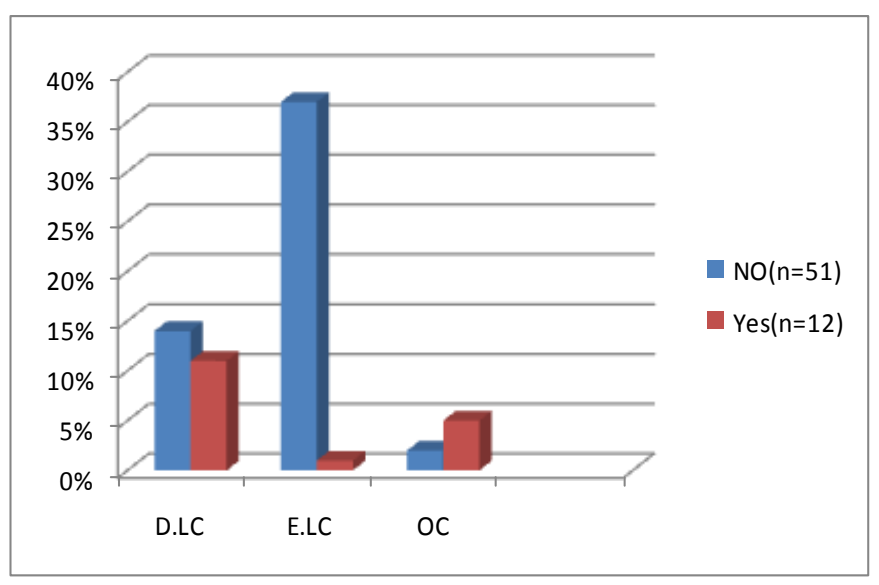

Table 8 Relationship between GB wall thickness,

Easy LC, Difficult LC and Conversion to OC

\begin{tabular}{|l|c|c|c|c|}
\hline $\begin{array}{l}\text { GB } \\
\text { thickness } \\
(\mathrm{n}=63)\end{array}$ & DLC (\%) & ELC (\%) & $\begin{array}{c}\text { Open } \\
\text { Conversion } \\
(\%)\end{array}$ & LC (\%) \\
\hline$<3 \mathrm{~mm}(\mathrm{n}=44)$ & $15(34)$ & $29(66)$ & $2(4.5)$ & $42(95.5)$ \\
\hline$\geq 3 \mathrm{~mm}(\mathrm{n}=19)$ & $10(52.6)$ & $9(47.4)$ & $5(26.3)$ & $14(73.7)$ \\
\hline$p$-value & \multicolumn{3}{|c|}{0.167} & \multicolumn{2}{c|}{0.012} \\
\hline
\end{tabular}

There were $19(30.2 \%)$ patients with GB wall thickness $\geq 3 \mathrm{~mm}$. Among them $10 \quad(52.6 \%)$ patients had difficulty during the procedure and 5 (26.3\%) patients required conversion to OC. Rest of the $44(69.8 \%)$ patients had GB wall thickness $<3 \mathrm{~mm}$, out of which $15(34 \%)$ patients had difficult LC and $2(4.5 \%)$ patients required conversion to OC. The finding of difficult LC was statistically insignificant ( $p$ value-0.167) but open conversion was significant ( $\mathrm{p}$ value-0.012) (table 8).

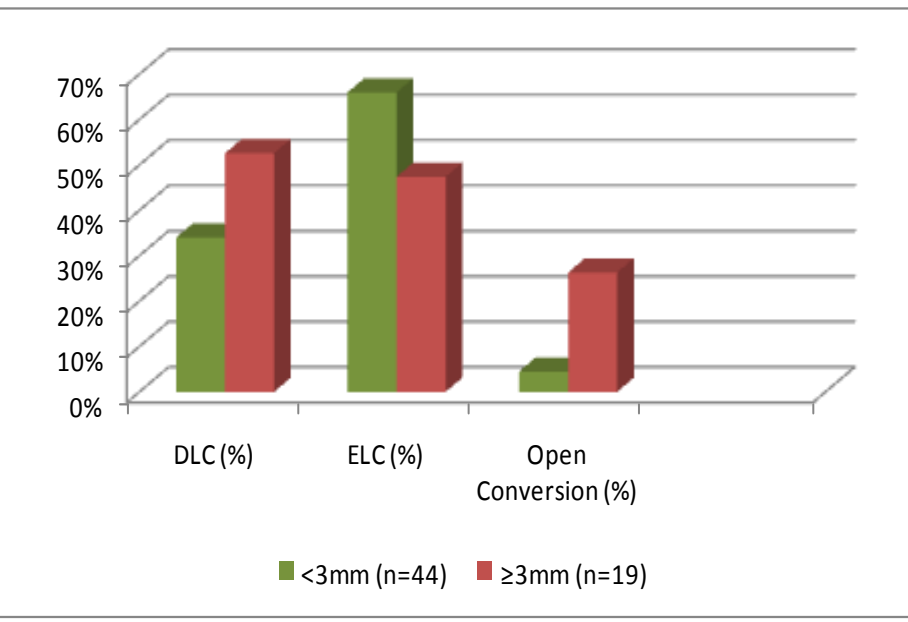

Table 9 Relationship between Number and size of the stone with DLC, ELC and Open conversion

\begin{tabular}{|l|c|c|c|c|}
\hline No. of GB stones & DLC (\%) & ELC (\%) & $\begin{array}{c}\text { Open } \\
\text { Conversion } \\
(\%)\end{array}$ & LC (\%) \\
\hline Solitary $(\mathrm{n}=16)$ & $6(37.5)$ & $10(62.5)$ & $1(6.3)$ & $15(93.7)$ \\
\hline Multiple (n=47) & $19(40.4)$ & $28(59.6)$ & $6(12.8)$ & $41(87.2)$ \\
\hline p-value & 0.0001 & & 0.0001 & \\
\hline Size of the gall stone \\
\hline$\geq 20 \mathrm{~mm}(\mathrm{n}=10)$ & $7(70)$ & $3(30)$ & $2(20)$ & $8(80)$ \\
\hline$<20 \mathrm{~mm}(\mathrm{n}=53)$ & $18(34)$ & $35(66)$ & $5(9.4)$ & $48(90.6)$ \\
\hline p-value & 0.0001 & & 0.0001 & \\
\hline
\end{tabular}

Multiple stones were found in 47 (74.6\%) patients and $19(40.4 \%)$ patients had difficult LC and 6 


\section{JMSCR Vol||05||Issue||12||Page 31413-31425||December}

$(12.8 \%)$ patients required conversion. Single stone was seen in $16(25.4 \%)$ patients and $6(37.5 \%)$ patients had difficulty during the procedure, while only $1(6.3 \%)$ patient had to be converted to OC. We also encountered $\geq 20 \mathrm{~mm}$ stone impacted at Hartmann's pouch in $10(15.8 \%)$ patients out of which difficulty during the procedure was found in $7(70 \%)$ patients and (20\%) patients were converted to OC. These findings were statistically significant ( $\mathrm{p}$-value $=0.0001$ and 0.0001 respectively) (Table 9). GB wall thickness, number of stones and size of the stone were the parameters based on which prediction of difficulty in performing LC was made. Ultrasonography was good at predicting difficulty in each component with exception of wall thickness.

\section{Relationship between Number of G.B. stone with} DLC, ELC and Open conversion

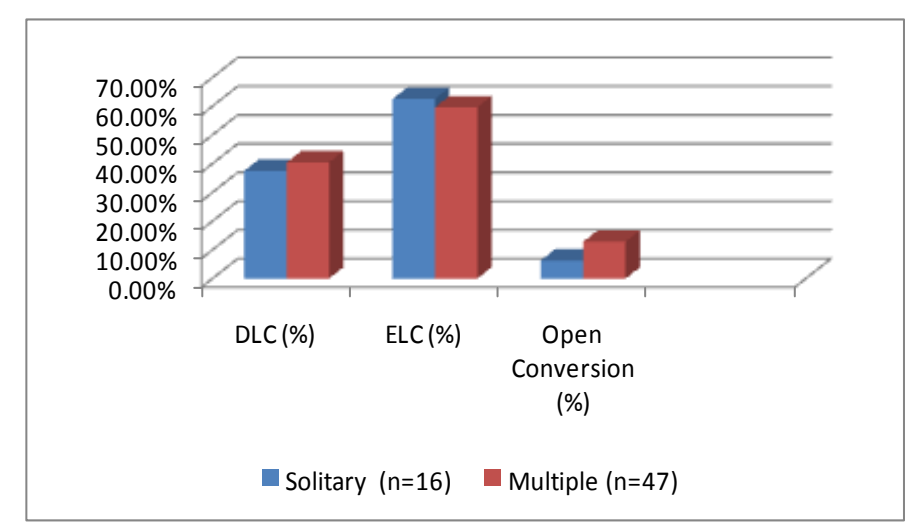

Relationship between size of G.B. stone with DLC, ELC and Open conversion

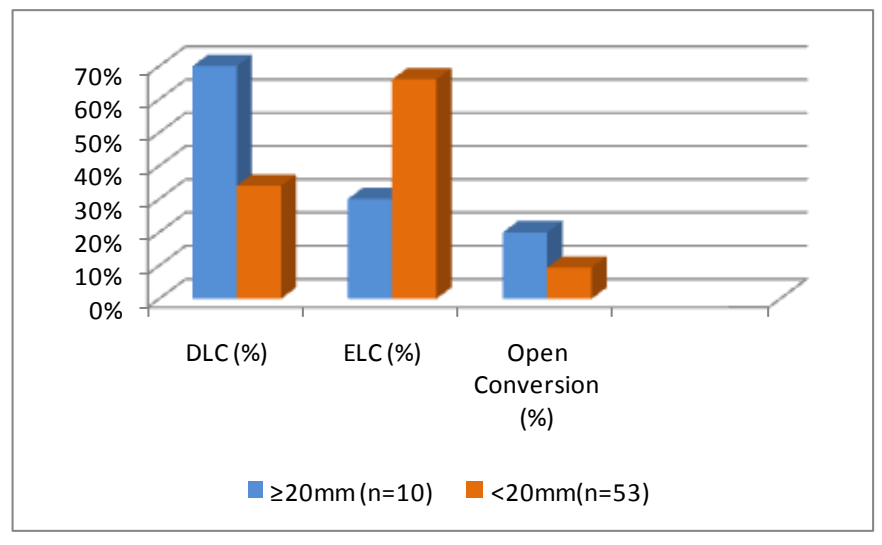

(I) Intra-operative causes for difficult LC
Table 10: Adhesion and Difficult LC and Conversion to OC

\begin{tabular}{|l|c|c|c|c|}
\hline $\begin{array}{l}\text { Adhesion } \\
(\mathrm{n}=63)\end{array}$ & DLC (\%) & ELC (\%) & $\begin{array}{c}\text { Open Conversion } \\
(\%)\end{array}$ & LC (\%) \\
\hline $\begin{array}{l}\text { Absent } \\
(\mathrm{n}=55)\end{array}$ & $20(36.4)$ & $35(63.6)$ & $6(11)$ & $49(89)$ \\
\hline $\begin{array}{l}\text { Present } \\
(\mathrm{n}=8)\end{array}$ & $5(62.5)$ & $3(37.5)$ & $1(12.5)$ & $7(87.5)$ \\
\hline $\mathrm{p}$-value & \multicolumn{2}{|c|}{0.305} & \multicolumn{2}{c|}{1.00} \\
\hline
\end{tabular}

Adhesions in Calot's triangle was present in 8 (12.7\%) patients out of 63 patients, where difficult LC was encountered in $5(62.5 \%)$ patients and only $1(12.5 \%)$ patient was converted to OC whereas in the group where adhesion was absent, $20(36.4 \%)$ patients out of 55 patients had difficult LC and 6 (11\%) patients had conversion. GB perforation with bile leak occurred in 4 patients while 2 patients had dropped stones in peritoneal cavity. Even though all the 6 patients had difficult LC, none of them were converted to OC (Table 10 and 11).

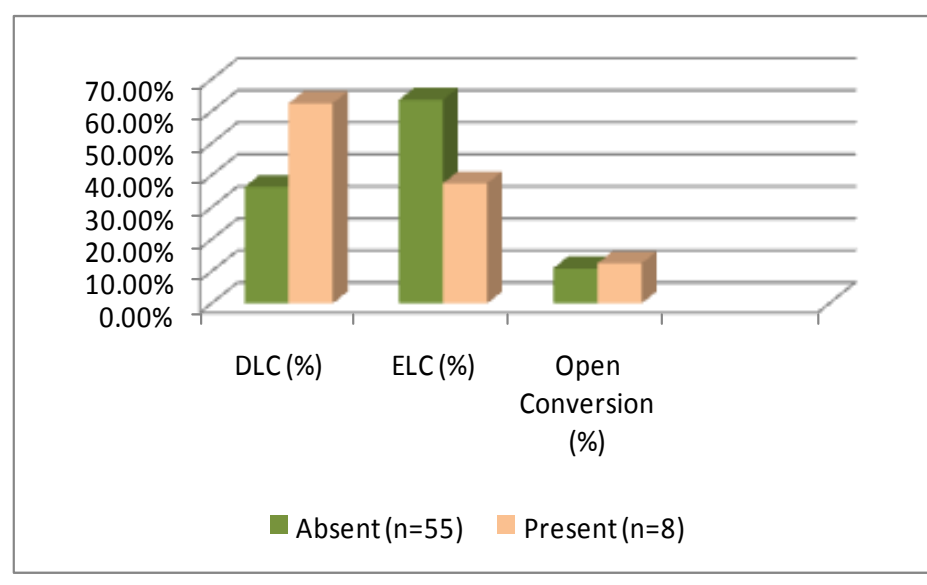

Table 11: GB Perforation and Difficult LC and Conversion to OC

\begin{tabular}{|l|c|c|c|c|}
\hline $\begin{array}{l}\text { GB } \\
\text { perforation } \\
(\mathrm{n}=63)\end{array}$ & DLC (\%) & ELC (\%) & $\begin{array}{c}\text { Open } \\
\text { Conversion } \\
(\%)\end{array}$ & LC (\%) \\
\hline No perforation & $19(33.3)$ & $38(66.7)$ & $7(12.3)$ & $50(87.7)$ \\
\hline Bile leak only & $4(100)$ & $0(0)$ & $0(0)$ & $4(100)$ \\
\hline Dropped stone & $2(100)$ & $0(0)$ & $0(0)$ & $2(100)$ \\
\hline p-value & \multicolumn{2}{|c|}{0.006} & \multicolumn{2}{|c|}{0.661} \\
\hline
\end{tabular}

(j) Conversion to open cholecystectomy

Total number of patients in this study was 63 out of which difficult LC was seen in $25(39.7 \%)$ patients and $7(11.1 \%)$ patients required conversion to OC. 


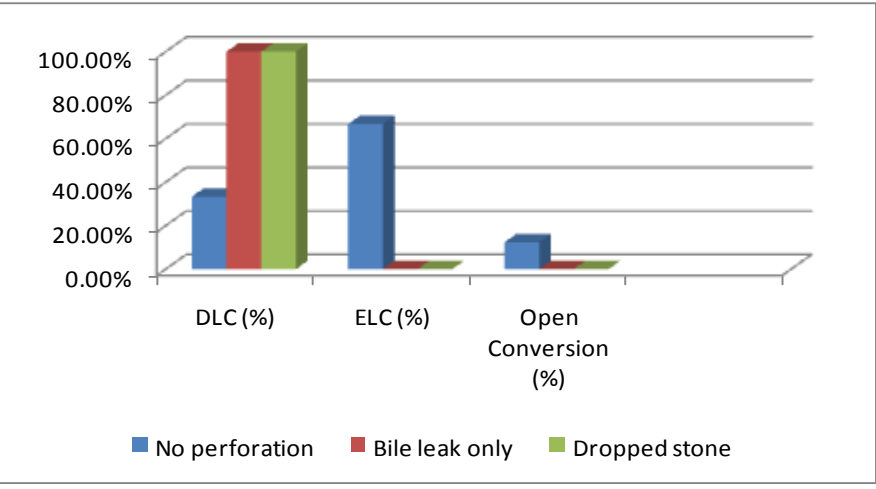

\section{Discussion}

Evident benefits of LC such as reduction in postoperative disability, cosmesis and early return to work have rendered it the procedure of choice for symptomatic cholelithiasis. With more frequent application of the procedure, it is expected that greater number of procedure would be difficult and might have to be converted to open cholecystectomy ${ }^{3}$. The chance of unwanted "surprise" waiting for surgeon during LC, such as dense adhesions and aberrant anatomy, are the same as those encountered during OC. However, conversion to open procedure is inevitable in some case of LC when surgeon faces difficulty. If there is benefit of reliable preoperative predictive factors, difficulty during procedure and chance of conversion can be estimated and patient can be informed of these possibilities and can be mentally prepared84.

While most of the previous studies in the literature were retrospective and evaluated various risk factors in terms of conversion to OC, our is a prospective study analyzing these risk factors as pre-operative predictors on clinical evaluation and ultrasonographic parameters. In the present study, a total of 63 patients were included and various variable analyzed for difficult LC were age, sex, BMI, previous abdominal surgery, attacks of cholecystitis, total leukocyte counts, ultrasonographic finding including thickness of GB, size and number of stones in GB and adhesions encountered during surgery.

Many researchers have found age $>60$ years as a predictor of difficult cholecystectomy ${ }^{3,4}$. Kama et $\mathrm{al}^{3}$ reviewed 1000 patients of cholelithiasis and found that $41.7 \%$ patients were $>60$ years of age and had conversion rate of $7 \%$ as compared to $3.9 \%$ in patients $<60$ years of age.

Most of the patients $51(81 \%)$ patients in the present study were $<50$ years and only $12(19 \%)$ patients were $>50$ years of age. Difficult LC was seen in $4(33.3 \%)$ patients and conversion rate was $16.7 \%$ in patients $>50$ years of age as compared to $9.8 \%$ in patients $<50$ years of age. Many authors have suggested that the reason for older age being at risk is due to a longer history of gallstones and increased number of acute attacks of cholecystitis.

Besides, elderly patients have a higher likelihood of complicated biliary pathology,6,7. Many investigators have reported higher incidence of difficult LC and higher conversion rate in male patients ${ }^{3,8,9}$. Kama et $\mathrm{al}^{3}$ reported incidence of conversion in $32 \%$ male and $11.2 \%$ female. Similar results were reported by Nachnani et $\mathrm{al}^{8}$ and Lipmanet $\mathrm{al}^{10}$.

However Kumar et $\mathrm{al}^{11}$, Liu et $\mathrm{al}^{4}$ and Rosen et $\mathrm{al}^{13}$ did not find significant difference in conversion rate in either sex which ranged from 10.41 to $41 \%$ in male as compared to 7.18 to $59 \%$ in female. No convincing explanation has been put forward for difficulty in LC in male by those who reported higher incidence of conversion in male as compared to female. However Kama et $\mathrm{al}^{3}$ suggested that male patients had more intense inflammation or fibrosis resulting in more difficult dissection both in Calot's triangle and through the plane between GB and liver, when compared with female patients with similar history ${ }^{3}$. The finding of present study revealed higher incidence of difficult LC in female patients $(41.5 \%)$ as compared to the male patients $(30 \%)$.

Also the conversion was not required in any male patients but 7 patients out of 53 females required conversions. This may be explained by the fact that sample size of male patients was small in the present study.

Many researchers have reported higher conversion rate with difficult LC in obese patients. ${ }^{4,8,13,14}$ Liu et al reported $25 \%$ of conversion in patients with 
morbid obesity, whereas Nachnani et al noticed BMI $>30 \mathrm{~kg} / \mathrm{m} 2$ as significant predictor of difficult cholecystectomy ${ }^{4,8}$. However in our study there were no patients with BMI >30 $2 \mathrm{~kg} / \mathrm{m} 2$. Most of the patients $(84 \%)$ in the present study had BMI between $18-25 \mathrm{~kg} / \mathrm{m} 2$ and $18(34 \%)$ patients of these had difficult cholecystectomy, and $4(7.6 \%)$ patients required conversion. Thus overweight patients i.e. BMI $>25 \mathrm{~kg} / \mathrm{m} 2$ is a predictor of difficult LC. However, studies conducted by Alponat et al and Kama et al did not reveal higher conversion rate in obese patients.

The criterion taken for obesity in their study was body weight $>80 \mathrm{~kg}$. Patient were considered as non-obese with weight $<80 \mathrm{~kg}$. This may be the reason for the discrepancy in their result as compared to other workers who based obesity upon $\mathrm{BMI}^{4,15}$.

Kumar et al while reviewing 512 patients undergoing LC reported that $150 \quad(35.15 \%)$ patients had previous history of acute cholecystitis. The conversion rate was $15.6 \%$ as compared to $3.6 \%$ in group without previous attack of cholecystitis93. Similarly, Tayebet al ${ }^{16}$ observed conversion rate with past history of cholecystitis as $8.2 \%$ as compared to $4.1 \%$ in patients without history of cholecystitis. In the present study, out of 63 patients, 30 patients had history of previous attack of cholecystitis and difficult LC was encountered in $46.7 \%$ patients. The conversion to OC was required in $13.3 \%$ patients. Among the patients with $\geq 2$ attacks of acute cholecystitis in past, $7(57.1 \%)$ patients had difficult LC, whereas conversion to open procedure was required in $28.6 \%$ patients. This observation is consistent with those reported in literature indicating that past history of cholecystitis is a predictor for difficult LC.

The relationship between number of attack of cholecystitis and difficulty encountered during surgery is more specific. In the previous studies the difficulty during LC and conversion rate was found to be less in patients with one attack of cholecystitis as compare to those who had two or more attacks. Out of 63 patients in present series, single attack of cholecystitis was seen in 23(36.5\%)patients, out of which 10(43.5\%) patients had difficult LC and 2(8.7\%) patients required conversion, as compared to $7(11.1 \%)$ patients who had more than one attack and difficulty was encountered in $4(57.1 \%)$ patients and 2(28.67\%)patients required conversion. Thus past history of cholecystitis and number of attack of cholecystitisis act as significant predictors of difficult LC.

Previous upper abdominal surgery has been listed as a concern because of adhesion formation, which causes bowel or other abdominal structures to adhere to the under surface of the abdominal wall .The potential for bowel injury during trocar placement or difficulty in visualization of Calot's triangle and the hepatobiliary structures has dissuaded some surgeons from using the laparoscopic procedure in patients with previous abdominal surgery ${ }^{5,6,7}$. On the other hand, the chance of unwanted "surprises," such as dense adhesions, awaiting the surgeon during LC are the same as those encountered during open cholecystectomy. In our study 5(8\%) patients had undergone previous abdominal surgery and among them 2(40\%) were difficult LC and none of the case was converted to open as compared to $7(12 \%)$ patients had without previous abdominal surgery. The rate of conversion to open cholecystectomy and the complication rate were not statistically significant to those found in the patients without prior surgery.

Other study shows that TLC more than 10000 is a predictive factor for difficult $\mathrm{LC}^{7}$ but in our study ten out of thirteen (76.9\%) associated with difficult LC. This is statistically significant in causing difficult LC, this is due to more no of patients were in acute period.

Dense adhesion and oedematous or friable GB were the main causes of difficult LC as reported in the past. Alponat et al observed that oedematous inflamed GB made exposure of Calot's triangle poor. Another problem interfering with good exposure was highly vascular adhesions present in this area ${ }^{15}$. Many investigators have reported that 
thick-walled GB was strongly associated with higher conversion rate during $\mathrm{LC}^{4,8,11,17}$.

Minimal GB wall thickness beyond which there is increased incidence of conversion was reported to be $4 \mathrm{~mm}$, by Kumar et al and others ${ }^{11,12}$.

However Kama et $\mathrm{al}^{3}$ considered GB wall thickness of $3 \mathrm{~mm}$ as significant. The reported incidence of conversion rate varies from $29.4 \%$ by Kumar et $\mathrm{al}^{11}, 30.8 \%$ by Kama et $\mathrm{al}^{3}$ and $32.8 \%$ by Rosen et $\mathrm{al}^{12}$. Slightly lower incidence reported by Kumar et $\mathrm{al}^{11}$ can be explained as these workers considered $4 \mathrm{~mm}$ thickness as compared to others who considered $3 \mathrm{~mm}$ thickness as significant $^{3,7,11}$. In our study, out of 63 patients, 19 (30.2\%) patients had evidence of GB wall thickness $\geq 3 \mathrm{~mm}$, out of which $10(52.6 \%)$ patients had difficulty during procedure and $5(26.3 \%)$ patients were converted to OC. This finding is in agreement with those reported in literature by various authors. The conversion rate in series of Liu et al was reported to be $13.1 \%$ in thick walled GB as compared to $7.2 \%$ in normal GB; however, they considered GB wall thickness as $4 \mathrm{~mm}$ as significant $^{4}$.

There are conflicting reports between number of stones and conversion rate. According to Kumar et $\mathrm{al}^{11}$, single stone has more chances of conversion than those with multiple, incidence being $13.3 \%$ and $5.2 \%$ respectively. However subsequent studies by Gabriel et $\mathrm{al}^{18}$ reported higher incidence of conversion in multiple stones as compared to single stone. In the present study, 47(74.6\%) patients had multiple stones, where difficulty during LC was encountered in 19 (40.4\%) patients while conversion rate was $12.8 \%$ as compared to $6.3 \%$ in patients with single stones. These results are comparable to others ${ }^{16,18}$. Jansen et al reported size of stone $>20 \mathrm{~mm}$ and those impacted at Hartmann's pouch were associated with difficult $\mathrm{LC}^{19}$. We also encountered stone impacted at Hartmann's pouch in $10(15.8 \%)$ patients out of which difficulty during the procedure was found in $7(70 \%)$ patients and $2(20 \%)$ patients were converted to OC. Impacted stones at Hartmann's pouch makes dissection difficult because of difficulty in holding GB at Hartmann's pouch and adequate visualization of elements of the Calot's triangle. Pericholecystitic fluid collection (PFC) is a ultrasonographic sign of acute inflammation. In our work, analysis showed that PFC was a significant predictor of a number of operational difficulties, which is correlated with many published studies which stated that the pericholecystitic effusion with other ultrasonographic signs of acute inflammation (edematous and thickened GB wall, Murphy's sign) is an important predictor of operational difficulties and a risk factor for conversion. Unclear anatomy and adhesions of the GB with surrounding structures in such patients are problems which surgeon is facing during surgery. It could be a potential cause of biliovascular lesions.

Adhesion in Calot's triangle results in disturbed anatomy of the area, where difficulty occurs in identifying the cystic artery and cystic duct and Calot's triangle becomes non feasible for LC. Various authors have reported incidence of $27.9 \%$ to $78.9 \%$ conversion rate in presence of adhesions in Calot's triangle and inability to identify anatomy correctly ${ }^{18,20,21}$. In the present study there were $8(12.7 \%)$ patients where adhesions were present in Calot's triangle. Out of these, $5(62.5 \%)$ patients had difficult LC but conversion to OC was required only in $1(12.5 \%)$ patients. The lower rate of conversion in this study may be due to the fact that most patients belonged to younger age group and had single attack of cholecystitis in past.

Chances of injury to GB during surgery occurs due to inability to hold GB with grasping forceps because of oedematous, friable or thin walled GB. Incidence of spillage of bile and dropped stones has been reported as $0.57 \%$ to $7 \%$ in literature. Though spillage of bile and dropped stones leads to difficulty in LC, however conversion is rarely required $^{22,23}$. In our study we had bile leak in 4 patients and bile leak with dropped stone in 2 
patients leading to difficult LC. However none of these patients were converted to OC.

In our study difficult LC was seen in 25(39.7\%) patients and $7(11.1 \%)$ patients required conversion to OC. Thus a conversion rate of $11.1 \%$ was observed. This is inconsistent with the previous studies where the conversion rates observed was 3 to $5 \%$. Table12 shows the comparison of conversion rate reported by different studies in different places in the world ${ }^{24-}$ 29 .

Table 12 Comparison of conversion rate in various series in different parts of the world.

\begin{tabular}{|c|c|c|c|}
\hline Kuldipet $\mathrm{al}^{24}$ & India & 6147 & $\begin{array}{c}0.36 \%(1.66 \% \text { Difficult } \\
\text { LC) }\end{array}$ \\
\hline Lim et $\mathrm{al}^{25}$ & Singapore & 149 & $11.5 \%$ \\
\hline Ishizakiet $\mathrm{al}^{26}$ & Japan & 1179 & $\begin{array}{c}5.3 \%(10.6 \% \text { Difficult } \\
\text { LC) }\end{array}$ \\
\hline 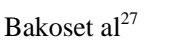 & Slovakia & 1535 & $5.7 \%$ \\
\hline Waseemet $\mathrm{al}^{28}$ & Pakistan & 216 & $4 \%$ \\
\hline Rosita et $\mathrm{al}^{29}$ & Iran & 793 & $9 \%$ \\
\hline This study & India & 63 & $11.1 \%$ \\
\hline
\end{tabular}

\section{Summary}

A total of 63 patients undergoing LC were studied for various factors leading to difficult laparoscopic cholecystectomy and conversion to OC. Thefollowing observations were drawn from thisstudy.

1) Difficult LC was seen in $41.7 \%$ patients below 50 years of age and $33.3 \%$ patients above 50 years of age. However, the conversion rate in difficult $\mathrm{LC}$ was much higher in patients above 50 years of age as compared to patients below 50 years age, being $50 \%$ and $23.8 \%$ respectively.

2) Overweight patients i.e. BMI between 25$30 \mathrm{~kg} / \mathrm{m}^{2}$ had $70 \%$ difficult LC and conversionrate was $30 \%$ as compared to $34 \%$ and $7.6 \%$ respectively in normal weight patients i.e. BMI between 18-24.9 $\mathrm{kg} / \mathrm{m}^{2}$.
3) Difficult LC was seen in $40 \%$ patients with previous abdominal surgery and $39.7 \%$ patientswithout previous abdominal surgery. However the conversion rate in difficult LC was $0 \%$ with previous abdominal surgeryas compared to $12 \%$ in patients without previous abdominal surgery.

4) Increased TLC of $\geq 11,000 / \mathrm{mm}^{3}$ had $76.9 \%$ difficult LC and conversion rate was $30.7 \%$ as compared to $30 \%$ and $6 \%$ respectively in patients with TLC $<11,000 / \mathrm{mm}^{3}$.

5) Difficult LC was seen in $91.7 \%$ patients with pericholecystic fluid collection in ultrasonograpy and $27.4 \%$ patients without pericholecystic fluid collection. However, the conversion rate in difficult LC was much higher in patients with pericholecystic fluid collection as compared to patients without pericholecystic fluid collection, being $41.7 \%$ and $3.9 \%$ respectively.

6) Patients with multiple GB calculi haddifficulty during $\mathrm{LC}$ in $59.6 \%$ and conversionto OC was required in $12.8 \%$ in comparison to $37.5 \%$ difficult LC and $6.3 \%$ conversion inpatients with single calculi.

7) Patients with stone $\geq 20 \mathrm{~mm}$ impacted in Hartmann'spouch had difficulty in $70 \%$ patients while $20 \%$ patients were converted to openprocedure. Whereas in patients where therewas no impaction of stone in Hartmann'spouch, the difficulty was encountered in $34 \%$ and conversion in $9.4 \%$.

8) Patients with adhesions in Calot's triangle had62.5\% difficult LC with conversion in $12.5 \%$ patients as compare to $36.5 \%$ difficult $\mathrm{LC}$ and $11 \%$ conversion in patients with no adhesionin Calot's triangle.

9) Difficulty was encountered in all patients who had GB perforation with bile leak and or dropped stone. 
10) GB perforation with bile leak (4 patients) and stone dropped (2 patients) in peritoneal cavity caused difficulty in performing LC. However conversion was not required in any case.

11) Among 63 cases difficult LC was seen in $25(39.7 \%)$ patients and $7(11.1 \%)$ patients required conversion to OC. Thus a conversion rate of $11.1 \%$ was observed.

\section{Conclusion}

Patients with ahigher number of predictors of difficulties need tobe operated by competent surgical team and must have priority in making operational programme in order to reduce health care costs and increase safety of surgery outcomes. So, the clinical and ultrasonographic findings may help to predict a difficult LC. This information may be useful to the patient, their relatives and the treating surgeon preoperatively.BMI, TLC, ultrasonographic findings of presence of pericholecystic fluid collection, multiple stone or stones $\geq 20 \mathrm{~mm}$ impacted in Hartmann'spouch, adhesion in Calot's triangle and gallbladder perforation is predictors of difficult LC. Thus need for conversion to open procedure is neither a failure nor a complication, but an attempt to avoid morbidity and mortality and ensure patients safety.

\section{References}

1. Conference NC. Gallstones and laparoscopic cholecystectomy. JAMA.1992; 269:1018-24.

2. Sharma SK, Thapa PB, Pandey A, Kayestha B, Poudyal S. Predicting difficulties during laparoscopic cholecystectomy by preoperative ultrasound. Kathmandu University Medical journal. 2007; 5(17):8-11.

3. Kama NA, Kologlu M, Doganay M, Reis E, Dolapci M. A risk scores for conversion from laparoscopic to open cholecystectomy. Am J Surg 2001; 181(6):520-5.
4. Alponat A, Kum CK, Koh BC, Rajnacova A, Goh PM. Predictive factors for conversion of laparoscopic cholecystectomy. World J Surg 1997; 21(6):629-33.

5. Liu CL, Fan ST, Lai CS, Lo CM, Chu KM. Factors affecting conversion of laparoscopic cholecystectomy to open surgery. Arch Surg 1996; 131():98-101.

6. Lo CM, Fan ST, Liu CL, Lai Edward CS, Wong J. Early decision for conversion of laparoscopic to open cholecystectomy for treatment of acute cholecystitis. Am J Surg 1997; 173(6): 513-7.

7. Cox MR, Wilson TG, Luck AJ, Jeans PL, Padbury RTA, Toouli J. Laparoscopic cholecystectomy for acute inflammation of gallbladder. Ann Surg 1993;218(5): 630-4.

8. Kum CK, Goh PMY, Isaac JR, Tekant Y, Ngoi SS. Laparoscopic cholecystectomy for acute cholecystitis. Br J Surg 1994; 81(11): 1651-4.

9. Nachnani J, Supe A. Preoperative perdiction of difficult laparoscopic cholecystectomy using clinical and $\mathrm{u} 1 \mathrm{tr}$ a s o n o g r a p h i c p a r ame te r s. In d i a n J Gastroenterology 2005; 24(1):16-8.

10. Curet MJ. Special problems in laparoscopic surgery. SurClin North Am2000; 80(4):1093-110.

11. Lipman JM, Claridge JA, Haridas M, Martin MD, Yao DC, Grimes KL et al. Preoperative findings predict c o nv e $r$ s i o n from 1 a paros copictoopen cholecystectomy. J Surgery 2007; 142(4):556-62.

12. Kumar S, Tiwari S, Agrawal N, Prasanna G, Khanna Rand Khanna A. Predictive factors for difficult surgery in laparoscopic cholecystectomy for chronic cholecystitis. The Internet Journal of Surgery 2008;16(2):254-8.

13. Rosen M, Brody F, Ponsky J. Predictive factors for conversion of laparoscopic cholecystectomy. Am J Surg 2002; 184(3):254-8. 
14. Simon MB. Gallstones: Prevalence, Diagnosis and Treatment. IMAJ 2001; 3:111-3.

15. Hutchinson $\mathrm{CH}$, Traverso LW, Lee FT. Laparoscopic cholecystectomy. Do preoperative factors predict the need to convert to open? SurgEndosc 1994; $8(8): 875-8$.

16. Tayeb M, Raza SA, Khan MR, Azami R. Conversion from laparoscopic to open cholecystectomy: Multivariate analysis of preoperative risk factors. J Postgrad Med 2005; 51(1):17-20.

17. Sharma SK, Thapa PB, Pandey A, Kayastha B Poudyal, Uprety KR, Ranjit S. Predicting difficulties during laparoscopic cholecystectomy by preoperative ultrasound. Kathmandu University Medical Journal 2007; 17(1):8-11.

18. Gabriel R, Kumar S, Shresth A. Evaluation of predictive factors for conversion of laparoscopic cholecystectomy. Kathmandu University Medical Journal 2009; 7(25):26-30.

19. Jansen S, Jorgensen J, Caplehorn J, Hunt D.Preoperative ultrasound to predict conversion in laparoscopic cholecystectomy. Surg Laparosc Endosc 1997; 7(2):121-3.

20. Shamin M, Memon AS, Bhutto AA, Dahri MM. Reasons of conversion of laparoscopic to open cholecystectomy in a tertiary care institution. J Pak Med Assoc 2009; 59(7):456-60.

21. Yatkin G, Vludag M, Gitgez B, Akgun I, Karakol S. Predictive factors for conversion of laparoscopic cholecystectomy in patients with acute cholecystitis. Bratisl Lel Listly 2009; 110(11):688-91.

22. Anand A, Singh S. Conversion in laparoscopic cholecystectomy: an evaluation study. JK Science 2007; 9(4):171-4.
23. Manukyan NM, Pakize D, Bahadir NG, Davut T, Cunhur Y, Rifat Y et al. Retained abdominal gallstonesduring laparoscopic cholecystectomy. Am J Surg 2005;189(4):450-2.

24. Singh K, Ohri A. Laparoscopic cholecystectomy is there a need to convert? J Minim Access Surg. 2005 Jun;1(2):59-62.

25. Chau CH, Siu WT, Tang CN, Ha PY, Kwok SY, Yau KK, et al. Laparoscopic cholecystectomy for acute cholecystitis: the evolving trend in an institution. Asian $\mathrm{J}$ Surg. 2006;29(3):120-4.

26. Ishizaki Y, Miwa K, Yoshimoto J, Sugo H, Kawasaki S. Conversion of elective laparoscopic to open cholecystectomy between 1993 and 2004. Br J Surg. 2006 Aug;93(8):987-91.

27. Bakos E, Bakos M, Dubaj M, PrekopI, Jankovic T. Conversion in laparoscopic cholecystectomy. BratislLek Listy.2008; 109(7):317-9.

28. Memon W, Khanzada TW, Samad A, Laghari MH. Laparoscopic cholecystectomy: conversion rate and its causes at Isra University Hospital, Hyderabad. Rawal Med J. 2008; 33:159-61.

29. Gholipour C, Fakhree MB, ShalchiRA, Abbasi M. Prediction of conversion of laparoscopic cholecystectomy to open surgery with artificial neural networks.BMC Surg. 2009 Aug;9:13. 